\title{
HISTÓRIA DO GALO (1950), DE LEONARDO ARROYO, E UM MODELO DE FORMAÇÃO DE LEITOR
}

\author{
HISTORY OF THE ROOSTER (1950), LEONARDO ARROYO, AND A MODEL OF \\ FORMATION OF READER
}

Vivianny Bessão de Assis ${ }^{1}$

\begin{abstract}
Resumo
Com o objetivo de contribuir para a produção de uma história, teoria e crítica específicas da literatura infantil e compreender o lugar ocupado por Leonardo Arroyo (1918-1985) na constituição de um discurso sobre a literatura infantil brasileira, focalizam-se aspectos de sua produção escrita relacionada à produção de literatura infantil, publicada em 1950, no Brasil. Mediante abordagem histórica, centrada em pesquisa documental e bibliográfica, desenvolvida por meio da utilização de procedimentos de localização, recuperação, reunião, seleção e ordenação de fontes documentais, vem-se elaborando instrumento de pesquisa contendo as referências de textos de e sobre Arroyo. Do conjunto dessas referências, destaca-se o livro História do Galo (1950), no qual é possível compreender aspectos da produção literária publicada nesse período e destinada à leitura de crianças na escola. Esse tipo de produção literária contribuiu com a disseminação de uma concepção de literatura infantil recorrente até a década de 1970, no Brasil.
\end{abstract}

Palavras-chave: Literatura infantil. Leonardo Arroyo. História da Educação.

\begin{abstract}
Aiming to contribute to the production of a history, theory and criticism of specific children's literature and understand the place occupied by Leonardo Arroyo (1918-1985), the constitution of a discourse on the Brazilian children's literature, focus is aspects of their written production related to the production of children's literature, published in 1950, in Brazil. Through historical approach, focusing on documentary and bibliographic research, developed through the use of procedures for the location, recovery, meeting, selection and ordering of documentary sources, it comes to designing the survey instrument containing references to texts and on Arroyo. Of all these references, there is the book History of the Rooster (1950), in which it is possible to understand aspects of literature published during this period and intended to reading children in school. This kind of literary production contributed to the spread of a conception of children's literature applicant until the 1970s, in Brazil.
\end{abstract}

Keywords: Children's literature. Leonardo Arroyo. History of Education.

\footnotetext{
${ }^{1}$ A autora é Doutoranda em Educação pelo Programa de Pós-Graduação em Educação (PPGE) da Faculdade de Filosofia e Ciências (FFC) da Universidade Estadual Paulista (UNESP), campus de Marília-SP. É integrante, desde 2012, do Grupo de Pesquisa: "História do Ensino de Língua e Literatura no Brasil" (GPHELLB). E-mail: viviannybessao@gmail.com
} 


\section{Introdução}

A partir de 1950, no Brasil, difundiu-se, no meio acadêmico, um novo modo de compreender a cultura e suas formas de disseminação. Nesse contexto, a educação procurou compreender como a escola se "exteriorizava" sobre a vida social e cultural das pessoas e como construía seus fazeres cotidianos. No campo da educação, a partir da década de 1960, passaram a se desenvolver pesquisas que procuravam refletir sobre como os saberes escolares eram produzidos e os efeitos que eles traziam para a sociedade. (VIDAL; GASPAR, 2010).

Com base nas ciências humanas e no conceito antropológico de cultura, as pesquisas na área da educação se voltaram para os sujeitos e suas experiências e para os objetos utilizados na escola. Os objetos materiais e bibliográficos passaram a ser compreendidos como cultura material. (VIDAL; GASZPAR, 2010).

O interesse de historiadores brasileiros da educação por investigar a cultura escolar a partir da década de 1960 incluiu diversas manifestações escritas, dentre elas, a literatura infantil, que também possibilitou um olhar sobre a escola. Segundo Mortatti (2001), a produção sobre literatura infantil tem início a partir da primeira metade do século XX, “[...] mediante publicação de livros de caráter ensaísta, manuais de ensino e alguns artigos, vão lentamente se destacando tematizações sobre um gênero subsumido nessa produção de livros para crianças: a literatura infantil.” (MORTATTI, 2001, p.179).

Segundo Mortatti (2001, p. 179), a partir de 1970,

[...] intensifica-se a produção científica sobre o gênero [...] processo para o qual concorrem, entre outros: a gradativa inserção e institucionalização da literatura infantil como matéria de ensino e/ou disciplina em currículos de licenciaturas em Pedagogia e Letras, a exemplo do que já vinha ocorrendo no Curso Normal -; a organização de entidades e projetos - governamentais ou não -, grupos acadêmicos e de pesquisa $[\ldots]$.

A partir da materialidade do mundo escolar e com o objetivo de conhecer os objetos que habitaram na escola, os espaços que ocuparam e os saberes que elaboraram é que vem se desenvolvendo algumas pesquisas e resultados de pesquisa como os apresentados neste texto.

Vidal e Gaspar (2010, p. 43), no artigo "Por uma história sensorial da escola e da escolarização", afirmam que a história material propõe compreender "[...] as múltiplas formas de apropriação dessa materialidade, de memorização do passado e de construção de laços afetivos entre os sujeitos e o mundo físico". Portanto, a materialidade dos objetos que 
circulam na escola e a sua permanência no tempo permitem a construção de inteligibilidades sobre o seu passado e presente, bem como sobre os sujeitos que convivem/conviveram com esses objetos. (VIDAL; GASPAR, 2010).

Em vista do exposto e com o objetivo de contribuir para a produção de uma história, teoria e crítica específicas da literatura infantil no Brasil e compreender o lugar ocupado pelo escritor, jornalista e historiador paulista Leonardo Arroyo (1918-1985), na constituição de um discurso sobre a literatura infantil brasileira, focalizo, aqui, o livro de litertura infantil História do Galo (1950), de Leonardo Arroyo, publicado pela editora Melhoramentos (São Paulo-SP). Nele, é possível observar a concepção de Arroyo em relação, dentre outras, às práticas de promoção da leitura e da literatura infantil.

Para a análise desse livro, utilizo o conceito de "configuração textual", Mortatti (2000, p. 31), que consiste em enfocar:

\begin{abstract}
[...] o conjunto de aspectos constitutivos de determinado texto, os quais se referem: às opções temático-conteudísticas (o quê?) e estruturais formais (como?), projetadas por um determinado sujeito (quem?), que se apresenta como autor de um discurso produzido de determinado ponto de vista e lugar social (de onde?) e momento histórico (quando?), movido por certas necessidades (por quê?) e propósitos (para quê), visando a determinado efeito em determinado tipo de leitor (para quem?) e logrando determinado tipo de circulação, utilização e repercussão.
\end{abstract}

\title{
1. Aspectos da vida, formação e atuação profissional de Leonardo Arroyo
}

Leonardo Arroyo é neto de família de portugueses, seus avós maternos, Laurentino Arroyo e Valentina Arroyo vieram de Portugal entre os anos de 1910 e 1911, fixando residência na cidade de Caieiras (SP). Os pais de Leonardo Arroyo, Anibal Arroyo e Theodora Braz, eram primos, casaram-se em 1915 e tiveram seis filhos: “[...] Leonardo o primogênito, Wilson, Ruth, Paulo, Maria Rosa e Valentina.” (SANT'ANA, 2002, p. 22). Leonardo Arroyo nasceu na cidade de São José do Rio Preto (SP), onde também viveu grande parte do seu período escolar. (ACADEMIA PAULISTA DE LETRAS, 1972, p. vii; SANT'ANA, 2002).

Leonardo Arroyo teve parte de sua alfabetização “[...] com professora particular [...]" (ACADEMIA PAULISTA DE LETRAS, 1972, p. vii). Iniciou seu curso ginasial no Ginásio

\footnotetext{
${ }^{2}$ Para maiores informações sobre o conceito de análise da configuração textual, ver Magnani (1997); Mortatti (2000).
} 
Municipal de Bebedouro (SP), mas, em 1929, com 11 anos de idade, precisou interromper o curso, porque sua família se mudou novamente para São José do Rio Preto (SP). Nessa cidade, se matriculou no Ginásio "São Joaquim" que depois se tornou o Instituto de Educação "Monsenhor Joaquim Gonçalves". (VASCONCELOS, 1985, p. 13).

Antes de concluir seus estudos no curso ginasial, Arroyo foi enviado para a casa de seus avós paternos em Lisboa, Portugal, pois seu pai queria que ele estudasse na Universidade de Coimbra. Permaneceu em Portugal por dois anos, retornando ao Brasil em 1932, quando “[...] concluiu os estudos (então ginasial) [...]”. (SANT'ANA, 2002, p.23).

Em 1936, com 18 anos de idade, começou sua carreira de jornalista no jornal $A$ Notícia, da cidade de São José do Rio Preto (SP). Entre os anos de 1938 e 1940, residiu na cidade de Santos (SP) e trabalhou no jornal A Tribuna, dessa cidade. (SANT'ANA, 2002, p. 27). Ainda no período de 1938 a 1940, colaborou com o Suplemento Literário dos jornais $A$ Tribuna (Santos-SP), Planalto (São Paulo-SP) e Gazeta Magazine (São Paulo-SP) e ingressou na Faculdade de Direito da Universidade de São Paulo, mas abandonou a faculdade no $2^{\circ}$. ano do curso para se dedicar a carreira de jornalista.

De acordo com nota do jornal Folha da Manhã (1952), no ano de 1945, Arroyo recebeu o seu primeiro prêmio literário intitulado "Tentativa", da Revista Atibaia (São PauloSP), com o livro de contos Ah, Solidão!. No ano de 1948, foi premiado em outro concurso promovido pelo jornal Diário de Notícia (São Paulo-SP), com o conto “O passado". Um ano depois, em 1949, ganhou outro prêmio intitulado "Fábio Prado" com o livro de contos Viagem para Málaga, patrocinado pela Associação Brasileira de Escritores ${ }^{3}$.

De 1958 a 1967, foi “[...] editor, diretor e redator da Página Literária [...]” do jornal Folha de S. Paulo (São Paulo-SP) e, em decorrência do prestígio social que tinha como escritor e jornalista do país, recebeu diversos prêmios, títulos e também assumiu alguns cargos no município de São Paulo (SP). (ACADEMIA PAULISTA DE LETRAS, 1972, p. ix).

\footnotetext{
${ }^{3}$ A União Brasileira de Escritores (UBE), “[...] foi criada em 1942 como Associação Brasileira de Escritores e teve como mentores Mario de Andrade e Sérgio Milliet. Sediada na Capital paulista, a UBE conta em seus quadros com aproximadamente 3800 associados [...], premiava diversos gêneros literários, como novelas, teatro, romance e contos. No ano de 1942, a Associação Brasileira de Escritores e a Sociedade Paulista de Escritores se fundiram, criando a Sociedade de Escritores Brasileiros. Em janeiro de 1958, a Sociedade de Escritores Brasileiros se tornou a União Brasileira de Escritores - UBE, em exercício até hoje e reconhecida como a mais antiga associação de escritores do país". Disponível em: 〈http://www.ube.org.br/historico.asp〉. Acesso em: 18 jan. 2014.
} 
Também, no período entre 1958 e 1967, foi membro da Comissão Estadual de Cultura, da Secretaria de Cultura do Estado de São Paulo. E, entre 1968 e meados de 1970, foi diretor do Departamento de Cultura no Governo Municipal do brigadeiro Faria Lima, na cidade de São Paulo (SP). À frente desse departamento, organizou a primeira Casa de Cultura, fundou o Corpo de Baile do Teatro Municipal e a Orquestra Jovem Sinfônica Municipal. Reabilitou a Revista do Arquivo Municipal de São Paulo e instituiu o curso de "História dos Bairros de São Paulo", “[...] destinado ao levantamento histórico dos bairros paulistanos”. (ACADEMIA PAULISTA DE LETRAS, 1972, p. ix-x).

Em julho de 1970, foi eleito, com 30 votos, membro titular da Academia Paulista de Letras ${ }^{4}$ e, em 14 de outubro de 1970, foi empossado na cadeira $n^{\circ} .21$.

Leonardo Arroyo faleceu em 13 de agosto de 1985, com 67 anos de idade, no Hospital Sírio-Libanês, na cidade de São Paulo (SP), em decorrência de derrame cerebral e pneumonia.

\section{Produção escrita de Leonardo Arroyo}

Do conjunto de diferentes tipos de textos escritos por Arroyo, pude localizar, até o momento, 159 referências, considerando, no caso dos livros, a $1^{\text {a }}$. edição ou edição mais antiga que localizei. (ASSIS, 2014).

Leonardo Arroyo foi autor de três livros de literatura infantil, dentre os quais Histórias do Galo (1950).

\section{Apresentação de Histórias do Galo (1950)}

O livro História do Galo foi publicado em 1950, pela editora Melhoramentos (São Paulo-SP). Até o momento, não localizei informações sobre alguma coleção ou série na qual esse livro possa ter sido publicado e nenhuma informação que confirme a existência de outras

\footnotetext{
${ }^{4}$ A Academia Paulista de Letras "[...] foi fundada em 27 de novembro de 1909. Trata-se de uma associação de direito privado sem fins econômicos, com sede na cidade de São Paulo (SP). Tem por objetivo promover a cultura do vernáculo e da literatura. A Academia é composta por 40 membros efetivos, 25 dos quais, devem ser domiciliados na cidade de São Paulo (SP), cada cadeira tem seu patrono, seu fundador e os sucessores. A cadeira de $\mathrm{n}^{\circ}$. 21, teve como patrono Antônio Carlos Ribeiro de Andrada Machado e Silva (1773-1845) e como fundador José Luís de Almeida Nogueira (? - 1914). Os acadêmicos que antecederam Leonardo Arroyo foram: Álvaro Guerra (1868-1942), Roberto Simonsen (1889-1943), José Freitas Vale (1870-1957), Plínio Barreto (1882-1958) e Ibrahim Nobre (1888-1970)". Disponível em: <http://www.academiapaulistadeletras.org.br>. Acesso em: 18 jan. 2014.
} 
edições desse livro. História do Galo (1950) tem formato de $20,5 \mathrm{~cm}$ x $17 \mathrm{~cm}$ e contém 47 páginas. Impressa em papel resistente e bastante colorida, a capa contém a ilustração de um galo grande e imponente com crista vermelha e penas nas cores cinza e laranja. Ao lado da ilustração do galo, aparece a ilustração de um pato branco, de estatura bem menor e menos imponente que o galo. Os dois animais estão posicionados de frente um para o outro. No fundo dessas ilustrações, aparece a ilustração de uma cerca branca, que representa madeira. Na parte inferior da capa, abaixo das ilustrações, consta informação sobre a editora.

\section{Figura 1: Capa de História do Galo (1950), de Leonardo Arroyo}

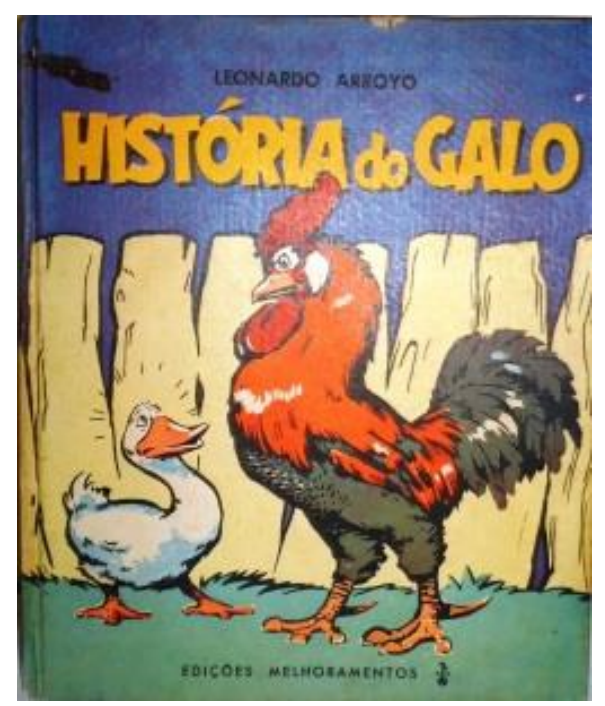

Fonte: Acervo do GPHELLB ${ }^{5}-$ Grupo de Pesquisa "História do ensino de língua e literatura no Brasil"

Conforme se observa na figura 1, a ilustração ocupa cerca de $70 \%$ da capa. Na parte superior da capa, em um fundo azul escuro e em letras destacadas na cor laranja, consta o título do livro. Acima do título, consta o nome do autor.

\footnotetext{
${ }^{5}$ O GPHELLB decorre do Programa de Pesquisa "História do Ensino de Língua e Literatura no Brasil" (PPHELLB) e, desse grupo e desse programa de pesquisa, em funcionamento desde 1994, resultaram o Projeto Integrado de Pesquisa "História do ensino de língua e literatura no Brasil" (PIPHELLB), em desenvolvimento, em etapas trienais, desde 1995, todos coordenados pela Profa. Dra ${ }^{\mathrm{a}}$. Maria do Rosário Longo Mortatti. O GPHELLB, o PPHELLB e o PIPHELLB estão organizados em torno de tema geral, método de investigação e objetivo geral, que são comuns a todas as pesquisas de seus integrantes. O tema geral - ensino de língua e literatura no Brasil - se subdivide em seis linhas de pesquisa: "História da formação de professores"; "História da alfabetização"; "História do ensino de língua portuguesa"; "História do ensino de literatura"; "História da literatura infantil e juvenil"; e "Memória e história da educação". Cadastrado no Diretório dos Grupos de Pesquisa do Brasil - CNPq; certificado pela UNESP. Atualmente, esse grupo tem como líder Prof ${ }^{a}$. Dra ${ }^{\mathrm{a}}$. Maria do Rosário Longo Mortatti e, como vice-líder, Prof $^{\mathrm{a}}$. Dr ${ }^{\mathrm{a}}$. Rosa Fátima de Souza.
} 
O livro tem uma página de rosto bem diferente da capa. No centro da página de rosto consta a ilustração do galo, igual ao da capa, mas, em formato bem menor e sem cores. Acima dessa ilustração, consta o título do livro em letras bastante destacadas, seguido da palavra "contos" em tamanho um pouco menor e entre parênteses. Acima do título e em tamanho menor, consta o nome do autor. Abaixo da ilustração, consta o nome do ilustrador: J. G. Villin. Abaixo da indicação do ilustrador, constam informações sobre a editora.

Na página seguinte, consta o índice com o título de quatro contos, a saber: "História do Galo", "Didi, o mosquito"; "Dom Carretel e Dona Linha" e "O Ratinho teimoso".

$\mathrm{Na}$ quarta capa há a divulgação de uma série publicada pela editora Melhoramentos (São Paulo-SP) intitulada "Walt Disney”. A série é apresentada da seguinte maneira': "As personagens que você conheceu nos engraçadíssimos desenhos animados são agora também heróis dêstes livros, que certamente farão o encanto de suas leituras.” (ARROYO, 1950, s.p.).

Ainda na quarta capa, abaixo dessas informações sobre a série "Walt Disney", consta a ilustração do personagem "Pato Donald" com os seus três sobrinhos. Abaixo dessa ilustração, constam os títulos publicados nessa série: "Aqui estão êles!"; "Mickey é o tal”; "Pato Donald e seus amigos"; "Pato Donald e seus sobrinhos"; "O piquenique do porquinho"; "O circo dos meninos-peixes"; e "Pato Donald na escola".

\section{Aspectos do conteúdo de Histórias do Galo (1950)}

Conforme mencionei, o livro História do Galo (1950) contém quatro contos: "História do Galo", que dá nome ao livro, "Didi, o mosquito"; "Dom Carretel e Dona Linha"; e "O Ratinho teimoso".

O conto "História do Galo" (1950) têm seis páginas, a história se passa no "país do Galinheiro", lugar calmo e "magnífico", cheio de "[...] sombra e sol, água à vontade, alimentação a horas certa [...]" (ARROYO, 1950, p. 5), onde galinhas, galos, patos e marrecos viviam satisfeitos. Os personagens principais são o Galo, a Franguinha Branca, o Marreco Preto, um homem e uma mulher que visitavam o galinheiro algumas vezes ao dia. A única interrupção na rotina do galinheiro era quando, de tempos em tempos, a mulher dizia ao

\footnotetext{
${ }^{6}$ Por se tratar de pesquisa histórica, utilizarei a ortografia original dos textos citados. 
homem a seguinte frase: "aquela está boa", após dizer isso, "alguém desaparecia" (ARROYO, 1950, p. 06).

O desaparecimento dos animais no galinheiro começou a preocupar os habitantes daquele lugar, para solucionar o problema decidiram discutir o assunto em "assembleia", de onde saiu o seguinte comunicado:

\section{CONCIDADÃOS DO PAÍS DO GALINHEIRO! \\ NÓS, REPRESENTANTES DO POVO, REUNIDOS EM ASSEMBLÉIA, COMUNICAMOS, PARA TRANQUILIDADE DE TODOS, QUE A EXPRESSÃO DOS HOMENS - AQUELA ESTÁ BOA - DEVE SER ACEITA COMO ORDEM NATURAL DO NOSSO DESTINO. NINGUÉM DEVE REVOLTAR-SE, MAS ACEITAR A ORDEM DAS COISAS COM CONFIANÇA NO FUTURO. (ARROYO, 1950, p. 06, grifos do autor).}

Os animais do galinheiro deveriam se conformar com essa rotina e, apesar de os animais mais jovens reclamarem sobre a repetição da palavra "ordem" no texto do comunicado, a rotina do local seguia normalmente, até a chegada de um galo diferente no galinheiro. O novo galo, apesar de ser bem recebido pelos outros animais, comportava-se de modo "egoísta" e "arruaceiro":

\footnotetext{
Ao ver o milho espalhado por todos os lados o novo habitante entendeu que tudo deveria ser somente seu. Começou a distribuir bicadas a torto e a direito, gritando: Saiam todos! Deixem-me comer sossegado! [...] - Quem ousa protestar? Quero saber para dar-lhe uma lição! (ARROYO, 1950, p. 8).
}

Devido a esse comportamento do novo habitante, os demais habitantes do galinheiro reuniram-se novamente em assembleia e Marreco Preto teve a ideia de dizer que a "fronteira" (porta de entrada do galinheiro) estava desafiando a "força" do galo. Com isso, o galo e a "fronteira" começaram a brigar e o galo acabou selecionado pelos humanos com a "terrível" frase: "aquela está boa". Depois disso, nunca mais foi visto no galinheiro. Desde esse dia, a paz voltou a reinar no galinheiro: “[...] os habitante se respeitavam, todo o mundo comia em paz, sem brigas, sem algazarra. A assembleia continuou a reunir-se para resolver os casos difíceis.” (ARROYO, 1950, p. 15).

O segundo conto do livro "Didi, o mosquito" (1950) tem oito páginas. A história se passa no "país da Cavalariça". As personagens principais são Didi, Dom Mosquito e Dona Mosquito, pais de Didi, e um mosquito velho e "estrangeiro" que apareceu por lá. Didi era um mosquito "teimoso", "barulhento", um "diabinho em pessoa" que não ouvia os conselhos dos 
pais e não ia à escola: "Dona Mosquito ralhava com êle, Dom Mosquito vivia a dar-lhe bons conselhos, mas o travêsso não levava a sério o que êle dizia." (ARROYO, 1950, p. 16).

Certo dia, Didi encontrou com o mosquito velho e "estrangeiro" que estava de passagem e seguia para o "país das Casas". Didi decidiu fugir com ele para esse novo lugar. Chegando lá, Didi desobedeceu ao mosquito velho, ao picar o nariz de um homem que dormia, ao invés de procurar alimento no açucareiro. Ao acordar, o homem encheu a casa de inseticida, Didi ficou "tonto" e quase foi apanhado pelo homem:

\footnotetext{
Não sabia mesmo como conseguira escapar da mão do homem. Pousou numa parede e ficou tremendo. O mosquito velho voltou e disse:

- Teimoso! Não sei por que permiti que você viesse comigo Estou quase arrependido. Vamos! (ARROYO, 1950, p. 23).
}

Com medo e saudade de casa, Didi pediu ao mosquito velho que o levasse de volta para o "país da Cavalariça". Didi arrependeu-se do "[...] fundo do coração. Esfregou as patinhas nos olhos, limpando-os e correu para casa. Dom Mosquito o esperava. Didi pediu-lhe perdão. Desde êsse dia foi-se transformado. Tornou-se, afinal, obediente e ia à escola todos os dias. Ninguém mais o vira fazer travessuras.” (ARROYO, 1950, p. 29).

O terceiro conto "Dom Carretel e Dona Linha" (1950) tem quatro páginas. A história se passa no "país do Cesto de Costura", os personagens principais são Dom Carretel, Dona Linha, tia Zefa e o sábio “[...] Dom Botão Preto, que foi promovido a filósofo do país." (ARROYO, 1950, p. 30). Dom Carretel era "orgulhoso", "soberbo" e "vaidoso", enquanto Dona Linha era "elegante", "muito branca" e sentia-se "triste" com os desaforos de Dom Carretel que vivia reclamando por ter que "carregar" Dona Linha para todo lugar. Botão Preto repreendia Dom Carretel dizendo: “- Dependemos todos uns dos outros. Sejamos bons. Temos um destino comum. Ai daqueles que não compreenderem esta verdade!" (ARROYO, 1950, p. 30).

Dom Carretel não aceitava o "destino" de carregar Dona Linha, ele queria "liberdade": "[...] quero viajar, conhecer outras terras, livre, inteiramente livre de Dona Linha, que me segura por todos os lados.” (ARROYO, 1950, p. 32). Mas Dom Botão Preto insistia:

No país dos homens, que são os nossos criadores, também há a dependência de que vos falo. As crianças, por exemplo, obedecem aos mais velhos...

[...] 
- Se tivésseis liberdade absoluta estaríeis longe, atirado daqui para ali, sofrendo quedas e acabaríeis tristemente. Aqui pelo menos há paz e limpeza. (ARROYO, 1950, p. 33).

Mesmo com toda a reclamação de Dom Carretel, a vida seguia normalmente no "país do Cesto de Costura", onde todos serviam as "mãos" de tia Zefa. Após um dia de trabalho, tia Zefa deixou Dom Carretel em cima de uma cadeira, nesse momento, Dom Carretel escorregou e saiu rolando pela sala de modo desgovernado até se desvencilhar totalmente de Dona Linha. Dom Carretel sentiu-se com muito medo e sozinho, somente após ter sido achado por tia Zefa e enrolado novamente em Dona Linha, sentiu-se bem novamente: "Desde êsse dia, Dom Carretel vive em paz no país do Cêsto de Costura. E gosta muito de Dona Linha e do seu instruído amigo Dom Botão Prêto.” (ARROYO, 1950, p. 34).

O quarto e último conto "O ratinho teimoso" (1950) tem sete páginas. A história se passa na dispensa da cozinha de um "velho casal". As personagens principais são Dom Rato, Dona Rata, Ratinho e o Gato Amarelo. Dom Rato era muito "cauteloso" e "experiente" "[...] não permitia estragos no país da Despensa. Não deixava que Dona Rata e Ratinho roessem os sacos de mantimentos apenas pelo prazer de destruir e nem que se atirassem às lingüiças e aos queijos de ralar, por esganação.” (ARROYO, 1950, p. 36).

Ratinho, por sua vez, era "desobediente", "teimoso" e "esganado", vivia visitando a dispensa escondido, sem a presença dos pais. A chegada de um novo queijo na dispensa deixou Ratinho com muita fome e com vontade de desobedecer.

Um dia, enquanto seus pais dormiam, Ratinho foi até a dispensa e começou a roer o queijo. Roeu tanto que fez um buraco no queijo e decidiu dormir nesse buraco. Quando acordou, foi surpreendido pelo Gato Amarelo.

\footnotetext{
Em breve o peralta já cabia inteiro dentro do queijo. Até seu rabinho, que era comprido, também ali cabia. Alargou o buraco com as patinhas. Sentia-se tão bem lá dentro, na frescura do queijo!" [...]

Lá fora, à entrada do buraco, dois grandes olhos se abriam para Ratinho. Era o Gato Amarelo, enorme! Êle guardava o buraco com o seu rosto de gigante. (ARROYO, 1950, p. 43).
}

Depois de muito tempo de conversa com o Gato Amarelo e depois de ter passado por muito medo, Ratinho aproveitou um minuto de sono do Gato Amarelo para escapar e voltar para casa. 
Um grande barulho encheu o silêncio da noite. Ratinho estava longe do gato, mas ainda não se sentia seguro e guinchava como um doido:

- Guiche! Dom Rato! Guiche! Dona Rata!

Aos saltos, tremendo, atravessou a fronteira e penetrou no país da Despensa.

- Ai, Dom Rato!, guichê! Ai Dom Rato! Que mêdo!

- Tudo porque você é teimoso e desobediente, Ratinho. (ARROYO, 1950, p. 46-47).

De modo geral, os contos apresentam de duas a quatro ilustrações, geralmente, elas ocupam a quarta e quinta páginas de cada conto. As ilustrações são bastante grandes, ocupam sempre uma página inteira do livro, e ao contrário da capa, não apresentam cores.

\section{Personagens}

Como se pode observar, as personagens que integram os contos de História do Galo (1950) são animais ou objetos com características comportamentais e sentimentais que se assemelham às dos humanos. Nesses contos, há sempre uma personagem em idade infantil, que se assemelha a uma criança, que comete "travessuras" e acaba por sofrer consequências ou é castigada e/ou corrigida pelos "adultos".

Os contos apresentam como núcleo temático modelos de comportamento que devem ser adotados pelas crianças leitoras, como modelos "corretos" para o convívio em sociedade. Em todos os contos, as consequências para as atitudes consideradas certas ou erradas são destacadas ao longo da narrativa.

Atitudes como egoísmo, gula, violência, teimosia, desobediência, ser "barulhento", não ir à escola, ser vaidoso, soberbo, querer "liberdade" e ter curiosidade de conhecer "outras terras", são atitudes condenadas e consideradas erradas. As personagens que apresentavam tais características sofreram algum castigo.

Em oposição a essas atitudes, comportamentos como ser obediente, ouvir os pais e os mais velhos, saber viver em comunidade, compartilhar o alimento sem desperdício, não ser guloso, estar satisfeito e conformado com o ambiente em que se vive, dialogar - "discutir em assembléia" - ao invés de cometer atos de violência, não ser preguiçoso, não se arriscar, são atitudes consideradas certas no livro. No final de cada conto, essas atitudes consideradas certas acabam sendo compreendidas e praticadas pelas personagens que, em geral, aprenderam a "lição". 
As personagens em idade infantil (ou que representam crianças) apresentam uma fragilidade legitimada pelo seu papel social e são "perdoadas" porque voltam a obedecer à família. As personagens que representam adultos ocupam um plano secundário ao das “crianças" em cada narrativa, sustentando as ações das "crianças", ora para castigá-las, ora para aconselhá-las. Desse modo, os contos contribuem para o estereótipo dos papéis sociais das famílias da época em que são produzidos os livros, colaborando por meio de exemplos.

Os modelos narrativos se organizam numa sequência de acontecimentos que se desenvolvem buscando um equilíbrio final para o desequilíbrio provocado, ou seja, a narrativa se centra na ação em busca pela resolução do problema e da "lição" que se quer transmitir.

\section{Espaço e tempo}

As narrativas acontecem em curtos espaços de tempo, configurando acontecimentos numa sequência cronológica, linear, que segue o fluxo dos acontecimentos. Desse modo, não há complexidade no encadeamento das ações, podendo ser mensuradas por meio da alternância de dias e noites. A marcação temporal dos contos é feita pelo narrador, de modo a facilitar a leitura.

A representação dos espaços é feita por ambientes comuns à literatura infantil da época, os quais lembram ambientes rurais, tais como: o galinheiro, o cesto de costura, o curral de cavalos, a despensa de uma cozinha. Esses ambientes conferem verossimilhança às histórias, a fim de permitir ao leitor identificação com o espaço representado.

Os contos se apresentam de forma muito semelhante às fábulas: animais com características humanas, e estruturam-se em torno de atitudes que geram uma espécie de conflito (sobretudo entre "gerações"), que ocasionam um clímax, sempre com o insucesso decorrente de uma atitude considerada errada. O desfecho ocorre com o arrependimento e resignação pelo aprendizado da lição moral.

\section{Momento histórico da produção de História do Galo (1950)}

A década de 1950, no Brasil, foi marcada pelo início da televisão e também considerada a "idade de ouro" do cinema. Nos anos 1950 vivemos os governos de Getúlio Vargas e de Juscelino Kubitschek, os quais, em linhas gerais, fomentaram o processo de 
industrialização nacional promovida pela abertura ao capital externo para investimento. Essa influência estrangeira ocorreu principalmente em decorrência do alinhamento político que o Brasil adotou juntamente com Inglaterra, França, Estados Unidos e União Soviética e contra os regimes nazi-facistas da Alemanha, Itália e Japão. (LAJOLO; ZILBERMAN, 1986).

Os Estados Unidos acabaram obtendo concessão definitiva no mercado brasileiro e passou a divulgar, dentre outros modelos culturais, adaptações de contos clássicos da literatura infantil mundial do Walt Disney para livros, filmes, desenhos animados e histórias em quadrinhos. Esse tipo de produção cultural influenciou a produção nacional de literatura infantil tanto nos textos literários, como na televisão, atraindo o mercado editorial de diferentes setores da sociedade. (LAJOLO; ZILBERMAN, 1986).

Criado por Walt Disney, o papagaio Zé Carioca tornou-se um símbolo do nacionalismo e também um símbolo do alinhamento entre os mercados e a produção cultural do Brasil e dos Estados Unidos. Segundo Lajolo e Zilberman (1984), as revistas em quadrinhos lideradas por "O Pato Donald" tornaram-se "[...] a encarnação do demônio para pais e professores habituados a leituras mais tradicionais.” (p. 93). Por outro lado, foi um tipo de produção cultural fortemente absorvida pelo mercado editorial brasileiro, conforme se pôde observa na quarta capa do livro História do Galo (1950), e na divulgação da série "Walt Disney”, publicada pela editora Melhoramentos (São Paulo-SP), formada de sete livros e vários contos.

Segundo Lajolo e Zilberman (1986), o modelo de cultura brasileira e cultura escolar que vigoravam nesse período era o que mantinha fortes vínculos com o nacionalismo. Essa vinculação se perpetuava também na produção de material de leitura para as crianças em idade escolar, inclusive nos textos de literatura infantil produzidos nesse período. Apesar de a influência norte-americana trazer novas experiências com a "cultura de massa" presente nos desenhos animados, filmes, histórias em quadrinhos, entre outros, as escolas e os educadores valorizavam a produção de modelos de comportamento nas histórias infantis, ou seja, valorizavam “[...] atitudes ideais e crianças exemplares”. (LAJOLO; ZILBERMAN, 1986, p.129).

[O]s autores dos anos 40 e 50 amassam o comportamento dos protagonistas, agora mais domésticos e dependentes, preocupados em demonstrar sua correção perante os adultos [...]. As crianças passam por vários aventuras geralmente seguidas de sentimentos de culpa [...]. (LAJOLO; ZILBERMAN, 1986, p. 130-131). 
Ainda segundo Lajolo e Zilberman (1986), apesar dos apelos de modernização e da influência do mercado cultural estrangeiro, os autores de literatura infantil desse período "demoraram" para compreender a mudança cultural e insistiam em temas ruralistas, como se pôde observar em alguns contos do livro História do Galo (1950). A produção de literatura infantil dessa década

[...] não deixa de estabelecer vínculos com a tradição, sobretudo quando esta é encarnada pelos grupos que, formados durante o apogeu da economia rural, mantinham alguma hegemonia política e constituíam os antepassados da classe que dominava a vida cultural. (LAJOLO, ZILBERMAN, 1986, p. 127).

Embora, até o momento, não tenha localizado informações sobre a existência de outras edições desse livro, a análise de História do Galo (1950) possibilita compreender alguns aspectos sobre determinado tipo de produção literária publicada nesse período no Brasil e destinada à leitura de crianças na escola. Por ter sido publicado pela Editora Melhoramentos (São Paulo-SP), que historicamente manteve uma relação com a publicação de materiais de leitura destinada à educação, considero, presumivelmente, que esse livro integrou um tipo de produção de leitura especificamente destinada para a escola e que contribuiu com a disseminação de uma concepção de literatura infantil bastante recorrente, no Brasil, pelo menos até o início da década de 1970.

\section{Considerações finais}

Como apresentado, publicado na década de 1950, o livro História do Galo, de Leonardo Arroyo, apresenta uma compreensão de literatura infantil que tem por finalidade desenvolver atitudes adequadas no convívio em sociedade. Conforme foi possível observar na apresentação dos enredos, a narrativa se constrói a partir do maravilhoso, da criatividade, da imaginação, no entanto, esses elementos tomam um segundo plano na narrativa em função do problema, do castigo e da lição que se querem ensinar, ou seja, o tom da instrução e do conselho acaba sobressaindo na leitura por meio da educação moral do público leitor.

A análise do livro História do Galo (1950) procurou integrar os estudos sobre a cultura material da escola que, conforme afirma Vidal e Gaspar (2010), disseminou-se a partir da década de 1960, no Brasil, bem como refletir sobre os saberes escolares produzidos na/para a escola e os efeitos dessa cultura na sociedade. Segundo Mortatti (2001), no caso brasileiro, o 
conceito e o valor da literatura infantil relacionam-se diretamente com o ensino da leitura na escola e com o seu momento histórico e social. O valor de uma obra literária, portanto, oscila com o tempo, dependendo dos sujeitos - autorizados - que a julgam.

No caso desse livro, é possível observar que a produção de literatura infantil desse período envolvia determinadas características do seu tempo histórico, destinava-se a um certo tipo de leitor (escolarizado), e tinha como objetivo produzir certos tipos de atitudes e/ou comportamentos em uma geração de leitores.

Por meio do livro aqui analisado é possível compreender aspectos importantes da atuação de Leonardo Arroyo relacionado, em especial, à história da educação, ao ensino da leitura e da literatura infantil, no Brasil, bem como compreender aspectos relacionados à sua produção escrita e à sua atuação profissional.

\section{Referências}

ACADEMIA PAULISTA DE LETRAS. Discursos de Leonardo Arroyo e Osmar Pimentel na sessão realizada a 14 de outubro de 1970. Rio de Janeiro, RJ: José Olympio Editora, 1972, 51 p.

ASSIS, Vivianny Bessão. Bibliografia de e sobre de Leonardo Arroyo: um instrumento de pesquisa, 2014. 49 p. (digitado).

ARROYO, Leonardo. História do Galo. São Paulo, SP: Melhoramentos, 1950.

FOLHA DA MANHÃ. Conferidos os prêmios Fábio Prado de 1949. São Paulo, 16 maio. Caderno único, 1950. p. 05.

Prêmio "Tentativa” de Literatura. São Paulo, 24 fev. Caderno único, 1952. p. 03.

LAJOLO, Marisa; ZILBERMAN, Regina. Literatura infantil brasileira: história \& histórias. São Paulo, SP: Ática, 1984.

Um Brasil para crianças: para conhecer a literatura infantil brasileira: história, autores e texto. São Paulo, SP: Global, 1986.

MAGNANI, Maria do Rosário Mortatti. Os sentidos da alfabetização: a "questão dos métodos" e a constituição de um objeto de estudo (São Paulo/1876-1994). 1997. 389f. Tese (Livre-Docência em Metodologia do Ensino de $1^{\circ}$ Grau: Alfabetização) - Faculdade de Ciências e Tecnologia, Universidade Estadual Paulista, Presidente Prudente, 1997.

MORTATTI, Maria do Rosário Longo. Os sentidos da alfabetização (São Paulo 1876/1994). São Paulo, SP: Ed. UNESP; Brasília: MEC/INEP/COMPED, 2000. 


\section{9}

MORTATTI, Maria do Rosário Longo. Leitura crítica da literatura infantil. Itinerários, Araraquara, 17: p.178-187, 2001.

SANT'ANA, Regina Angélica Cazarini. Leonardo Arroyo: escritor e jornalista. São José do Rio Preto, SP: Artes Gráficas Paulista, 2002.

VASCONCELOS, Geraldo. Nota biográfica. In: 10 contos escolhidos: Leonardo Arroyo. Brasília: Horizonte; Brasília, DF: INL, 1985, p. 13-14.

VIDAL, D. G.; GASPAR DA SILVA, V. Por uma história sensorial da escola e da escolarização. Linhas, v.11, n. 2, 2010, p. 29-45. Disponível em:

<http://www.periodicos.udesc.br/index.php/linhas/article/view/2127>. Acesso em: 10 jul. 2014. 